\title{
Üniversite tercihinin bulanık aksiyomatik tasarım ile değerlendirilmesi
}

\author{
Hanife PALABIYIK ${ }^{1, *}$, Sümeyye BAYINDIR ${ }^{1}$, Özer UYGUN ${ }^{2}$ \\ ${ }^{1}$ Sakarya Üniversitesi, Mühendislik Fakültesi, Endüstri Mühendisliği Bölümü, Sakarya \\ ${ }^{2}$ Sakarya Üniversitesi, Yapay Zeka Sistemleri Uygulama ve Araştırma Merkezi, Sakarya \\ Gelis Tarihi (Received Date): 13.03.2019 \\ Kabul Tarihi (Accepted Date): 22.10.2019
}

$\ddot{O} z$

Üniversite seçimi bireylerin gelecek hayatlarını etkileyen en önemli kararlardan birisidir. Fakat üniversite sayısının fazlalı̆̆l ve her üniversitenin sunduğu imkânların çeşitliliği üniversite seçimini zorlu bir problem haline dönüştürmekte ve bu problemin çözümünde de devreye çok kriterli karar verme yöntemleri girmektedir. Bu yöntemlerden biri de uygulamada kullanılan Aksiyomatik Tasarım yöntemidir. Aksiyomatik Tasarım sistem ve tasarım aralıklarını dikkate alarak her alternatif için bilgi içeriklerini üretir ve üretilen bilgi içeriklerinden en küçük olanı seçmeyi hedefler. Bu doğrultuda kriterlere göre üniversite tercihini sözel olarak ifade etmek insan düşünce yapisina daha uygun olduğundan bu çalışmada dilsel ifadeler kullanılarak bulanık Aksiyomatik Tasarım uygulanmıştır. Ayrıca her kriterin önem derecesi gerçek hayatta aynı olmadığı için öncelikle Bulanık AHP ile ağırlıklar hesaplanmıştır. Ardından ağırlıklı bulanık Aksiyomatik Tasarım kullanılmış ve elde edilen sonuçlar karşılaştırılmıştır.

Anahtar Kelimeler: Bulanık aksiyomatik tasarım, bulanık AHP, üniversite seçimi.

\section{Evaluating university choice by fuzzy axiomatic design}

\begin{abstract}
University selection is one of the most important decisions that affect the future life of individuals. However, due to the high number of universities and the opportunities offered by each university, university selection becomes a challenging problem and multi-criteria decision-making methods are included in the solution of this problem. One of these methods is the Axiomatic Design method which generates information content for each

\footnotetext{
* Hanife PALABIYIK, hanife.palabiyik@ gmail.com, https://orcid.org/0000-0003-3580-4482

Sümeyye BAYINDIR, bayindirsumeyye @ gmail.com, https://orcid.org/0000-0003-0649-5836

Özer UYGUN, ouygun@ sakarya.edu.tr, https://orcid.org/0000-0002-8437-7678
} 
alternative considering the system and design intervals and aims to select the smallest of the information content produced. In this direction, fuzzy axiomatic design has been applied by using linguistic expressions in this study since linguistically expressing the choice of university based on criteria is more suitable for human nature. In addition, since the importance of each criterion is not the same in real life, first, the weights were calculated with Fuzzy AHP. Then, fuzzy axiomatic design was used, and the obtained results were compared.

Keywords: Fuzzy axiomatic design, fuzzy AHP, selection of university.

\section{Giriş}

Her birey hayatını devam ettirebilmek adına belli mesleklere yönelir ve bu seçtiği meslek sayesinde yaşamını idame ettirebilir. Meslek edinmenin en etkili ve en başarılı hali ise alınan güzel bir eğitimdir. Bireyler ilkokuldan lise sonuna kadar olan süreçte kendini tanıyıp, yönelmek istediği mesleği kafasında belirler ve eğitimin son basamağı olan üniversite tercihini o şekilde yapar. Ülkemizde lisans ve ön lisans eğitimi veren farklı kalitelerde yüzlerce üniversite vardır ve bu sayı her geçen gün artmaktadır. Alternatif üniversite sayısı artıkça tercih yapma olasılığı da bir o kadar zorlaşmaktadır.

Meslek seçimi bireyler için çevre ile sosyal ilişkiler kurmayı sağlayan ve bireylere işe yaradıkları duygusunu hissettiren bir etkinlik alanıdır. Çünkü bireyler bu seçimi yaparken ilerde yaşamak istedikleri hayatı da seçmiş olurlar[1]. Fakat meslek seçimi yapmış olmak aslında bir son değil her şeyin başlangıcıdır. O meslekte çok iyi yerlere gelip başarılı olabilmek için çok iyi bir eğitim alınması gerekmektedir. İşte bu noktada aslında üniversite seçiminin ne kadar önemli olduğu konusu devreye girmektedir.

Öğrenciler okumak istedikleri bölüme karar verdikten sonra ciddi bir araştırma içerisine girerler. $\mathrm{Bu}$ araştırmaların en önemli nedeni ise kaliteli bir eğitim alıp, eğitimlerinin sonunda yani mezun olduktan sonra edindikleri bilgiler ile kolayca iş fursatlarını yakalayabilmektir. Ancak üniversite sayısının fazlalığından dolayı her yıl üniversiteler binlerce üniversite mezunu vermekte ve kaliteli eğitim alamayan birçok üniversite mezunu işsiz kalmaktadır.

Bireyler üniversite tercihi yaparken birçok kriteri göz önünde bulundurur. Bu kriterler örnek olarak; ulaşım, üniversitenin modern, bilimsel ve teknolojik altyapısı, üniversitenin eğitim verebilen yeterli miktarda akademik kadrosunun varlığı, üniversitenin şehri, bu şehrin sosyo-kültürel olanakları, okunmak istenen bölüme dair o şehrin öğrenciye sağlayacağı imkânlar, üniversitenin çevresinde bulunan yurt olanakları ve ulaşım gibi faktörler sayılabilir.

Üniversitenin eğitimdeki değişimleri takip ederek modern bir eğitim vermesi, üniversite binalarının derslik, laboratuvar, kulüpler vb. açısından bilimsel ve teknolojik altyapısının güçlü olması üniversite seçimini etkileyen önemli faktörlerdendir. Öğrencinin ders gördüğü ortamda kendini rahat hissetmesi, öğrendiği bilgileri laboratuvar ortamlarında test ederek görebilmesi ve çeşitli aktivitelerin yapıldığı kulüplere katılması eğitimin durağan bir halden zevkli bir hale gelmesini sağlar. 
Üniversitede bulunan akademik kadronun da sayısal olarak yeterli olması, öğrencilerin farklı ögretim görevlilerinden ders alabilme imkânı yaratır ve istedikleri zaman gidip istediklerini sorabilmeleri de kaliteli bir eğitimin gerekliliklerindendir.

Bir üniversiteyi tercih esnasında üst sıralara taşıyan en önemli etkenlerden biri de üniversitenin etrafında bulunan yurt imkânlarıdır. Çünkü üniversite çevresinde yurtların bulunmaması birçok öğrenciyi hem maddi hem manevi açıdan zarara uğratmaktadır. Yurtların üniversiteye uzak olması öğrencilerin derse yetişip yetişmeme konusunda strese sebep olacak, derslerin verimsiz geçmesine de neden olurken aynı zamanda yol masrafından dolayı maddi olarak da dezavantaja neden olmaktadır.

Üniversitede okunmak istenen bölüme ait şehrin belli bir alt yapısının olması da tercih edilen kriterlerden biridir. Örneğin mühendislik fakültesi okumak isteyen bir öğrenci seçim yapmak istediği üniversitenin sanayi ayağı ve staj imkânlarının iyi olmasını bekler. Bu şekilde eğitimini aldığı teorik bilgilerini birçok firmada pratik bilgiye dönüştürebilir.

Üniversitelerde eğitim almanın dışında üniversite çevresindeki sosyal kültürel olanaklar da birçok öğrenciyi üniversite seçiminde cezbetmektedir. Üniversite çevresinde gezilecek turistik yerlerin olması, alışveriş merkezlerinin olması stresli geçen eğitim hayatına kısa bir mola verdirebilir.

Üniversite seçiminde birçok kriter olduğu gibi üniversitenin altyapısı da söz konusu kriterlerden biridir. Tercih işlemi yapılırken her üniversite için bu kriterler ayrı ayrı incelenmeli ve kriterleri diğerlerine göre daha iyi sağlayan üniversite tercih edilmelidir. Literatüre bakıldığında bu tarz bir çalışmanın yapılmadığı görülmüş ve genelde üniversite seçimini etkileyen faktörlerin belirlenmesi üzerine çalışmalar yapılmıştır. Bu konuda yapılan çalışmalara örnek olarak; Konjoint Analizi ile üniversite tercihlerini etkileyen faktörlerin belirlenmesi [2], Anova Testi yapılarak 306 Öğrencinin Üniversite tercihlerine bakarak üniversite tercihinde etkili olan kriterlerin belirlenmesi [3], Manova Analizi ile Üniversite öğrencilerinin lisans yönetimi eğitimi için belirli bir üniversiteyi seçerken dikkate aldığ kriterlerin incelenmesi [4] ve öğrencilerin üniversite ve bölüm seçiminde gördükleri faktörler üzerine çalışma [5] verilebilir.

Üniversite seçimi gibi çok alternatifli ve çok kriterli problemlerin çözümünde çok kriterli karar verme tekniklerinden faydalanılmaktadır. Çok kriterli karar verme sayesinde tüm alternatifler her bir kriter açısından tek tek değerlendirilir ve istenilen kriterleri en iyi oranda sağlayan alternatif optimum çözüm yani en iyi çözüm olarak kabul edilebilir.

Sayısal verilerin olmadığı ve kriterlerin derecesinin dilsel olarak ifade edildiği durumlar bulanık olarak ifade edilir. Örneğin üniversite çevresinin sosyal kültürel olanakları sayısal olarak ifade edilmesi her zaman mümkün değilken dilsel yani sözel olarak kötü, orta, iyi şeklinde ifade edebilir. Bu durumda çok kriterli karar verme tekniklerinden bulanık olarak yararlanmak gerekebilir.

Bulanık çok kriterli karar verme tekniklerinden birisi de Aksiyomatik Tasarımdır. Aksiyomatik Tasarım da kriterler için uzmanlar tarafından tasarım aralıkları belirlenir, daha sonra alternatifler için de sistem aralıkları hesaplanır. Tasarım ve sistem aralıklarının ortak alanı sayesinde her alternatif için bilgi içeriği hesaplanır. En küçük bilgi içeriğini üreten alternatif, en iyi alternatif olarak tercih edilir. 
Üniversite seçim probleminde bulanık aksiyomatik tasarım uygulamasına rastlanmamış fakat bu yöntemin kullanıldığı bir beyaz eşya üreticisi [6] ve bir bebek maması üreticisi için tedarikçi seçim problemlerinden faydalanılmıştır [7].

\section{Metodoloji}

Bu çalışmada, kriter ağırlıklarını elde etmede Bulanık Analitik Hiyerarşi Prosesi (BAHP) kullanılmıştır. Literatürde BAHP ile ilgili oldukça fazla çalışma olduğundan ve bu çalışmanın asıl konusunun bulanık aksiyomatik tasarım olmasından dolayı BAHP hesaplamaları ile ilgili ayrıntılı bilgiler verilmemiştir. Bu kısımda aksiyomatik tasarım ve bulanık aksiyomatik tasarım yöntemleri anlatılmıştır.

\subsection{Bulanık analitik hiyerarşi prosesi}

Klasik AHP yönteminde karar vericiler sonuçları hesaplayabilmek adına Satty'nin [1-9] skalasını yani gerçek sayıları kullanmakta ve bu durum değerlendirme sürecini zorlaştırmakla beraber belirsizliklere yol açmaktadır. Bu nedenle akademik çalışmalarda karar verme sürecindeki belirsizlikleri bulanık mantık yöntemi kullanarak gidermek mümkün hale gelmiştir. Çalışmanın ağırlıklı bulanık aksiyomatik tasarım kısmında Chang tarafından önerilen Genişletilmiş Analiz Yöntemi kullanılmıştır [8]. Chang'e göre ikili karşılaştırmalar üçgensel bulanık sayılarla temsil edilmektedir. Bulanık AHP (BAHP) sayesinde karar vericiler ikili karşılaştırmalar yaparken "Vasat", "Zayıf", "Mükemmel" gibi dilsel ifadeleri ele alarak araştırma yapabilmektedir. Çalışmalarda dilsel ifadelerin ele alınması, karar vericilerin anketleri yorumlamasını kolaylaştırmaktadır [9]. Bulanık AHP hiyerarşik bulanık problemleri çözmek amacıyla geliştirilmiştir [10]. BAHP sürecinde karar matrisinde yer alan ikili karşılaştırmalar tasarımcının vurgusuna göre dönüştürülen bulanık sayılardır [11]. BAHP'nin bu özelliğiyle en önemli artısı, çok kritere sahip problemleri ele alırken sağladığı kolaylıktır.

\subsection{Aksiyomatik tasarım}

Karar verme problemlerinde kararı veren için en önemli nokta, seçilen alternatifin istenen kriterleri en üst seviyede karşılamasıdır. Bundan dolayı karar vermeyi sağlama ve karar vericilerin işlerini kolaylaştırma adına sürekli olarak yeni karar verme yöntemleri araştırılmaktadır. Hız ve verimlilik açısından Aksiyomatik Tasarım (AT) bunlardan birisidir.

Aksiyomatik Tasarım müşterilerin taleplerini gereksinimleri doğrultusunda tespit ederek, fonksiyonel ihtiyaçlarla tasarım parametrelerini oluşturur ve devamında tasarım parametrelerinden nihai sonuca ulaşmak için Aksiyomatik Tasarım metodolojisini uygular. Çok kriterli karar verme problemlerinin çözümünde müşteri istekleri kapsamında sistematik bir yaklaşım sunmaktadır.

Aksiyomatik Tasarım; tasarım alanını bilimsel yapmak için geliştirilen bir tasarım metodudur. Suh [12] tarafından Massachusetts Teknoloji Enstitüsünde geliştirilen Aksiyomatik Tasarımın amac1; karar vericilerin daha kreatif olması, deneme-yanılmayı minimum yapma, rassallığı azaltma ve seçenekler arasından en iyisini bulma olarak ifade edilmiştir. Bu yöntem ile belirlenen tasarım alanında istenilen kriterlere uygun sistematik bir arama yapar ve gereksiz aramaları en aza indirerek en olurlu alternatifin seçimini kolaylaştırır. 
Suh tasarımı, "Neyi hedefliyoruz?" ve "Bu hedefe nasıl ulaşabiliriz?" sorularının birlikte çözümlenmesi olarak tanımlar [13]. Aksiyomatik Tasarım için en önemli unsur tasarım aksiyomlarıdır. Bu metodolojide bağımsızlık aksiyomu ve bilgi aksiyomu olmak üzere 2 tasarım aksiyomu bulunmaktadır. Bu aksiyomlar sayesinde alternatifler karşılaştırılarak en iyisi seçilir.

Bağımsızlık aksiyomu, fonksiyonel ihtiyaçlarla tasarım parametreleri arasındaki ilişkiye bakar. Burada tanımlanan fonksiyonel ihtiyaçlar problemin kriterleridir ve birbirinden bağımsız olmak zorundadır. Bilgi aksiyomu bilgi içeriğini temsil eder ve seçenekler arasında minimum bilgi içeriği üreten sonuç optimum alternatifi oluşturur.

Aksiyomatik tasarım yönteminin kullanılmasının birçok avantajı bulunmaktadır. Karar verme sürecine yardımcı bir sistem olması, daha gerçekçi ve doğru kararlar verilmesini sağlaması ve çok kriterli ve seçenekli karar verme problemlerinde en iyi çözümü bulmayı sağlaması bu avantajlardan bazılarıdır.

Bilgi aksiyomu bilgi içeriğini temsil eder. Bilgi içeriği $\left(I_{i}\right)$, ifade edilen bir fonksiyonel ihtiyacın (Fİ) gerçekleşme olasılığı $\left(p_{i}\right)$ olarak açıklanır. Bilgi içeriği denklemi Shannon eşitliği olarak bilinir.

$I_{i}=\log _{2}\left(1 / p_{i}\right)$

Bilgi küçük birimlerden oluşur. Karşılanması gereken çok fazla fonksiyonel ihtiyaç oluşacağından bilgi içeriğginin elde edilebilmesi için logaritmik fonksiyon kullanılmıştır. $\mathrm{N}$ tane Fİ olduğu durumda bilgi içeriği bu olasılıkların toplamına eşittir. Bu toplam şu şekilde hesaplanmaktadır.

$$
I_{\text {sistem }}=\sum_{i=1}^{n} \log _{2}\left(1 / p_{i}\right)
$$

Hesaplanan bu toplam 1'e eşit olursa bu bilgi içeriğinin 0 olduğu, bir veya birden fazla olasılık 0 olduğunda ise bilgi içeriğinin sonsuz olduğu anlamına gelmektedir [12].

Gerçekleşme olasılığı, Fİ'nin tasarım aralığı (dr) ve Fİyi sağlayacak tasarım için sistem aralığ $1(\mathrm{~s} r)$ belirlenerek bulunabilir. Bir FI'nin sistem olasılık dağılım fonksiyonu uniform olduğunda, tasarımcı tarafından belirlenen 'tasarım aralığı' ve sistemin gerçekleştirdiği 'sistem aralığı'nın kesiştiği bölge çözümün bulunduğu yani kabul edilebilir alandır [14]. Sistem olasılık dağılım fonksiyonu uniform ise gerçekleşme olasılığı Fi;

$$
P_{i}=\frac{\text { Ortak Aralık }}{\text { Sistem Aralı } \breve{g l}}
$$

$\mathrm{Bu}$ formülden hareketle bilgi içeriğinin hesabı şu şekildedir;

$$
l_{i}=\log _{2}\left(\frac{\text { Ortak Aralık }}{\text { Sistem Aralı } \breve{g l}}\right)
$$

Eğer Fİ, sürekli rasgele değişken ise bilgi içeriğinin hesabı şu şekildedir;

$$
P_{i}=\int_{d r_{1}}^{d r_{u}} P_{s}\left(F \dot{I}_{i}\right) d F i_{i}
$$


Sistemin olasılık yoğunluk fonksiyonunun integrali alınarak bütün sistem aralığının gerçekleşme olasılığı bulunur. Örnek verilecek olursa tasarım aralığının en düşük sınırı $d r_{1}$, üst tasarım aralığının sınırı, $d r_{u}$ olur.

Sadece FÍnin sağlandığı bölge, yani tasarım aralığı ve sistem aralığı arasında kalan ortak bölge $\left(c_{r}\right)$ olarak gösterilir. Bu durumda, sistem aralığı alanının, ortak bölgenin alanına bölümü, tasarım için belirlenen hedefin gerçekleşme olasılığına eşittir [14].

$$
I=\log _{2}\left(A_{s r} / A_{c r}\right)
$$

Şekil 1'de sistem aralığı belirlenmiş olup fonksiyonel ihtiyaçlara göre olasılık yoğunluk fonksiyonu verilmiştir [15].

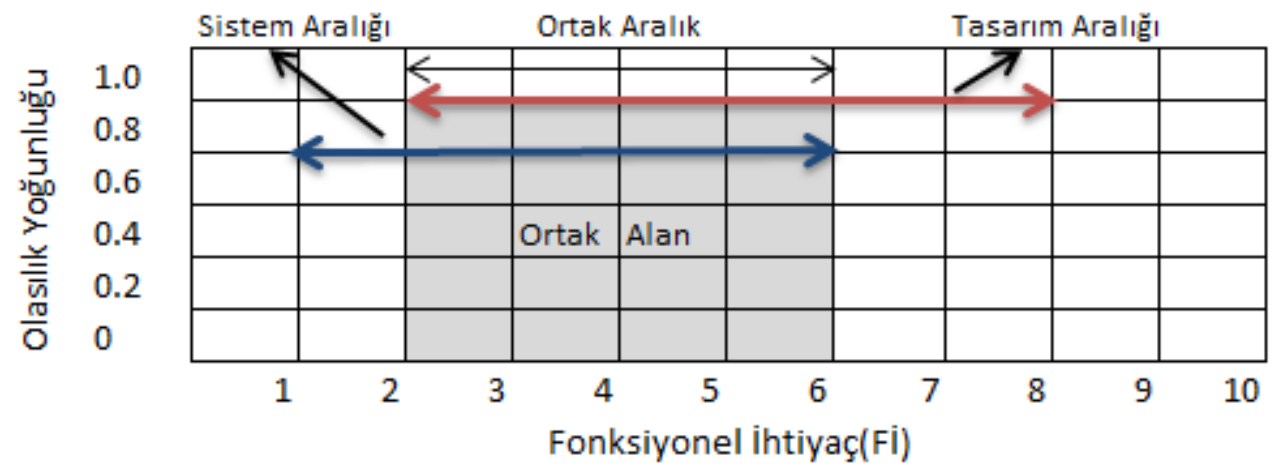

Şekil 1. Fİ'nin sistem olasılık dağılımı, ortak aralık, tasarım ve sistem aralı̆̆ı.

$\mathrm{FI}_{\mathrm{i}}$, sürekli değişken olduğu durumlarda sistem aralığı belirlenmiş olan fonksiyonel ihtiyaçlara göre olasılık yoğunluk fonksiyonu Şekil 2'de verilmiştir [15].

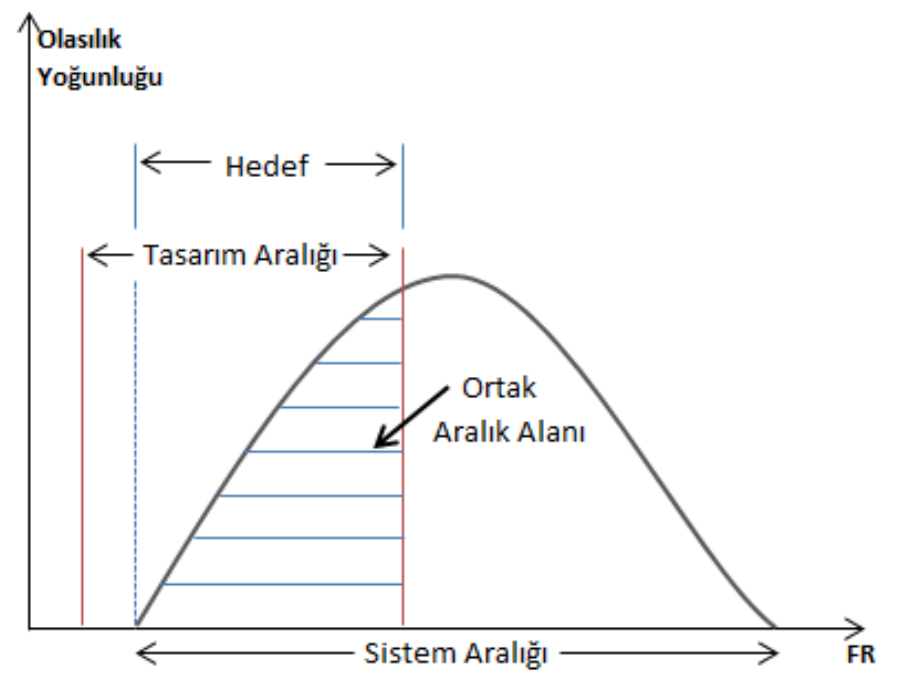

Şekil 2. FI'nin olasılık yoğunluğu, ortak aralık, tasarım ve sistem aralığı.

\subsection{Bulanık aksiyomatik tasarım}

Veriler kesin olarak bilindiğinde çok kriterli karar verme yöntemleri kullanılırken, verilerin belirsiz olduğu durumlarda ise kullanılan yöntemlerden birisi bulanık aksiyomatik tasarımdır. Değerleri belli olan veriler ifade edilirken gerçek sayılar kullanılırken kesin değerler olmadığı durumlarda ve sayısal değerlerin yerine dilsel 
değişkenler kullanıldığında bu verilerden sonuç elde etmek için belli kurallar altında sayısal forma dönüştürülmelidir. Bu aşamada kullanılan en önemli araç bulanık küme teorisidir. Sayısal olmayan değerleri sayısallaştırabilmek adına dilsel değişkenlere ait üyelik fonksiyonlarının gösterimi Şekil 3'deki gibidir [15].

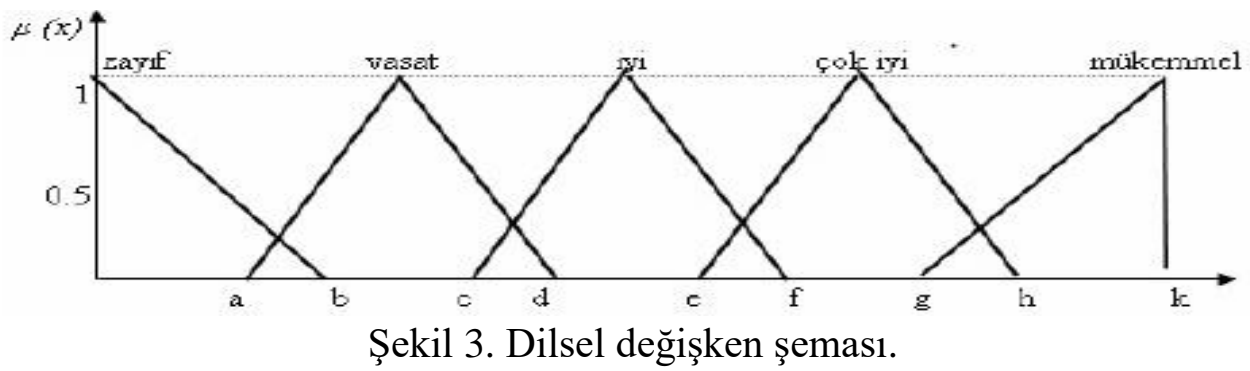

Aksiyomatik Tasarım uygulamasında, fonksiyonel ihtiyaçlar için sistem aralığı ve tasarım aralığı daima belli bir alanda tanımlanmayabilir. Belirli bir değerin altında veya üstünde bir değere yaklaşık olarak gösterilebilir ve üçgensel ya da yamuksal bulanık sayılarla bu veriler ifade edilir.

Ortak alan, Bulanık AT'de üçgensel ya da yamuksal bulanık üyelik fonksiyonları ile gösterilir ve bu alan üçgensel ya da yamuksal bulanık sayıların kesiştiği bölgedir. Şekil 4'de görüldügü gibi, ortak alan sistem aralığının bulanık üçgensel alanı ile tasarım aralığının bulanık üçgensel alanın arasındaki kesiş̧im bölgesidir [15].

Sonuç olarak bilgi içeriği hesabı aşağıdaki gibidir.

$$
I=\log _{2}\left(\frac{\text { Sistem Tasarımının Uçgensel Bulanık Alanı }}{\text { Ortak Alan }}\right)
$$

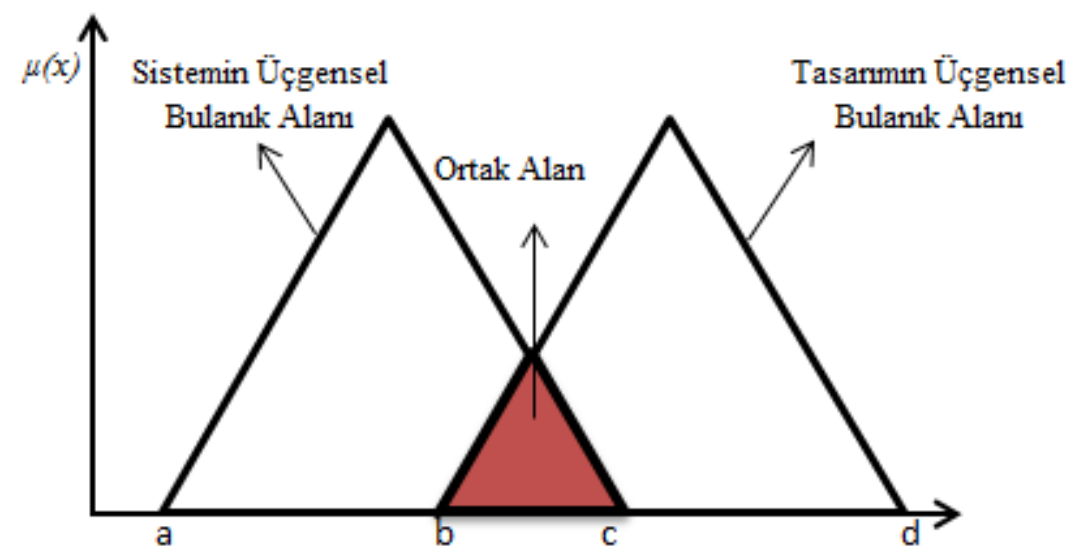

Şekil 4. Sistem ve tasarım aralıklarının ortak alanı.

\subsubsection{A Ăırlıklı bulanık aksiyomatik tasarım}

Bulanık AT'de her kriterin ağırlığı bilgi içeriklerinde hesaplanırken eşit olarak kabul edilmiş fakat gerçek hayatta her kriter farklı ağırlık değerine $\left(\mathrm{w}_{\mathrm{j}}\right)$ sahip olabilir. $\mathrm{Bu}$ durumda bilgi içeriklerini hesaplayabilmek adına için ek olarak aşağıda verilmiş olan eşitlik kullanılır ve bu ifade "Ağırlıklı Bulanık Aksiyomatik Tasarım” uygulaması olarak tanımlanır [15]. 


$$
I_{i j}=\left\{\begin{array}{ll}
{\left[\log _{2}\left(\frac{1}{p_{i j}}\right)\right]^{1 / w j}} & , 0 \leq I_{i j} \leq 1 \\
\left.\log _{2}\left(\frac{1}{p_{i j}}\right)\right]^{w j} & , I_{i j} \geq 1 \\
w_{j} & , I_{i j}=1
\end{array}\right\}
$$

\section{3. Üniversite seçiminde bulanık aksiyomatik tasarım uygulaması}

Çalışmada Mühendislik fakültesinde okumak isteyen öğrenciler için Türkiye'de mühendislik dalında en başarılı olan 6 üniversite arasından belli kriterler altında seçim yapılmak istenmektedir. Bunun için AT yöntemiyle üniversite seçimi ele alınmıştır. Çalışmada üniversite seçimini etkileyen alternatifler incelenen makaleler ve üniversite seçiminde öğrencilerin fikirleri dikkate alınarak belirlenmiştir. Yapılan araştırmalar sonucunda öğrenciler için üniversite seçimini etkileyen 5 önemli kriter belirlenmiştir.

Bunlar;

1. Akademik Kadro: Seçilen üniversitedeki hoca sayısı yeterliliğini ifade eder.

2. İş Dünyası ile Etkileşim: Üniversite çevresindeki sanayi potansiyelini ifade eder.

3. Sosyal Kültürel Olanaklar: Üniversite çevresindeki sosyal yaşamı ifade eder.

4. Modern, Bilimsel, Teknolojik Altyapı: Üniversitenin öğrenciye sunduğu imkanlardır.

5. Yurt İmkanı: Üniversitenin bulunduğu bölgenin yurt ihtiyacına cevap verebilme yeteneğidir.

Belirlenen alternatifler doğrultusunda mühendislik alanında en iyi üniversiteyi seçebilmek adına Bulanık Aksiyomatik Tasarım yaklaşımı ve her bir kriterin AHP ile ağırlıklandırıldığı duruma bakılarak ‘Ağırlıklı Bulanık Aksiyomatik Tasarım' yaklaşımı uygulanmıştır. Araştırma için 6 üniversite ele alınmış ve bu üniversiteler hakkında detaylı bilgi ise o üniversitelerde okuyan öğrenciler tarafından sağlanmıştır.

\subsection{Bulanık aksiyomatik tasarım uygulaması}

Aksiyomatik tasarım yönteminde bilgi aksiyomunun uygulanabilmesi için ilk olarak aksiyomatik tasarım gereksinimlerinden bağımsızlık aksiyomunun sağlanması gerekmektedir. Bu uygulamada kriterlerin sağladığı fonksiyonel ihtiyaçlar yani belirtilen alternatifler birbirinden bağımsız olduğu varsayılmıştır. Aksiyomatik Tasarımının uygulanabilmesi için öncelikle bilgi içeriklerinin hesaplanması gereklidir. Her bir alternatife ait bilgi içeriklerinin hesaplanması için ilk önce fonksiyonel ihtiyaçların (FI) yani kriterlerin tasarım aralıklarının belirlenmesi gerekmektedir. Bu amaçla uzman kişiler tarafından belirlenen tasarım aralıkları (kısıtlar) Tablo 1'de verilmiştir. Dilsel değişkenler için kullanılan bulanık üyelik fonksiyonları Şekil 5'de verilmiştir.

Tablo 1. Alternatifler için tasarım aralıkları.

\begin{tabular}{lc}
\hline Alternatifler & Tasarım Aralı̆̆ \\
\hline Akademik Kadro (Sayısına göre) & $(5,14,14)$ \\
İş Dünyası ile Etkileşim & $(7,14,14)$ \\
Sosyal Kültürel Olanaklar & $(5,10,14)$ \\
Modern, Bilimsel, Teknolojik Altyapı & $(4,14,14)$ \\
Yurt İmkânı & $(2,14,14)$ \\
\hline
\end{tabular}


Üçgensel üyelik fonksiyonlarını görsel olarak elde edebilmek ve formüllerde kullanılan alanları hesaplayabilmek için java tabanlı matematik yazılımı GeoGebra kullanılmıştır.

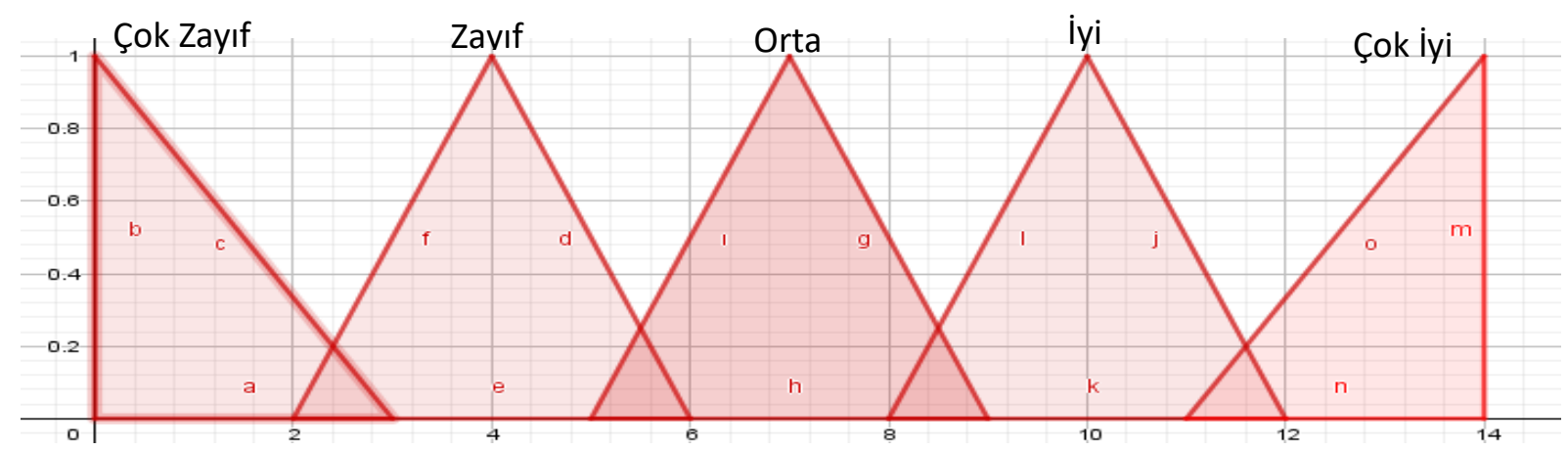

Şekil 5. Dilsel ifadeler için bulanık üyelik fonksiyonları.

Kriterlere ait tasarım aralıkları bulunduktan sonra her alternatifin her kriterine dair tasarım aralıkları belirlenmiştir. Belirlenen tasarım aralıkları Tablo 2'de verilmiştir.

Tablo 2. Üniversiteler için tasarım aralıkları.

\begin{tabular}{lccccc}
\hline Üniversite & $\begin{array}{c}\text { Akademik } \\
\text { Kadro }\end{array}$ & $\begin{array}{c}\text { İş Dünyası İle } \\
\text { Etkileşim }\end{array}$ & $\begin{array}{c}\text { Sosyal } \\
\text { Kültürel } \\
\text { Olanaklar }\end{array}$ & $\begin{array}{c}\text { Modern, } \\
\text { Bilimsel, } \\
\text { Teknolojik } \\
\text { Altyapı }\end{array}$ & Yurt İmkanı \\
\hline 1. Üniversite & İyi & Çok İyi & İyi & Orta & İyi \\
2.Üniversite & Orta & Orta & İyi & Orta & Çok İyi \\
3.Üniversite & İyi & Çok İyi & İyi & Orta & Çok Zayıf \\
4.Üniversite & Çok İyi & İyi & Çok İyi & Zayıf & Çok İyi \\
5.Üniversite & İyi & İyi & İyi & İyi & Orta \\
6.Üniversite & Zayıf & Çok İyi & Orta & Çok İyi & İyi \\
\hline
\end{tabular}

Aksiyomatik Tasarım için verilen Denklem 8 kullanılarak her üniversite için bilgi içeriği hesaplamaları yapılabilir. Örneğin aşağıda 1.üniversite için akademik kadro açısından bilgi içeriği hesaplanmış ve Şekil 6'da modellenmiştir.

$\boldsymbol{I}_{\mathrm{ak} 1}=\log _{2}(2 / 1,58)=0,340$ 


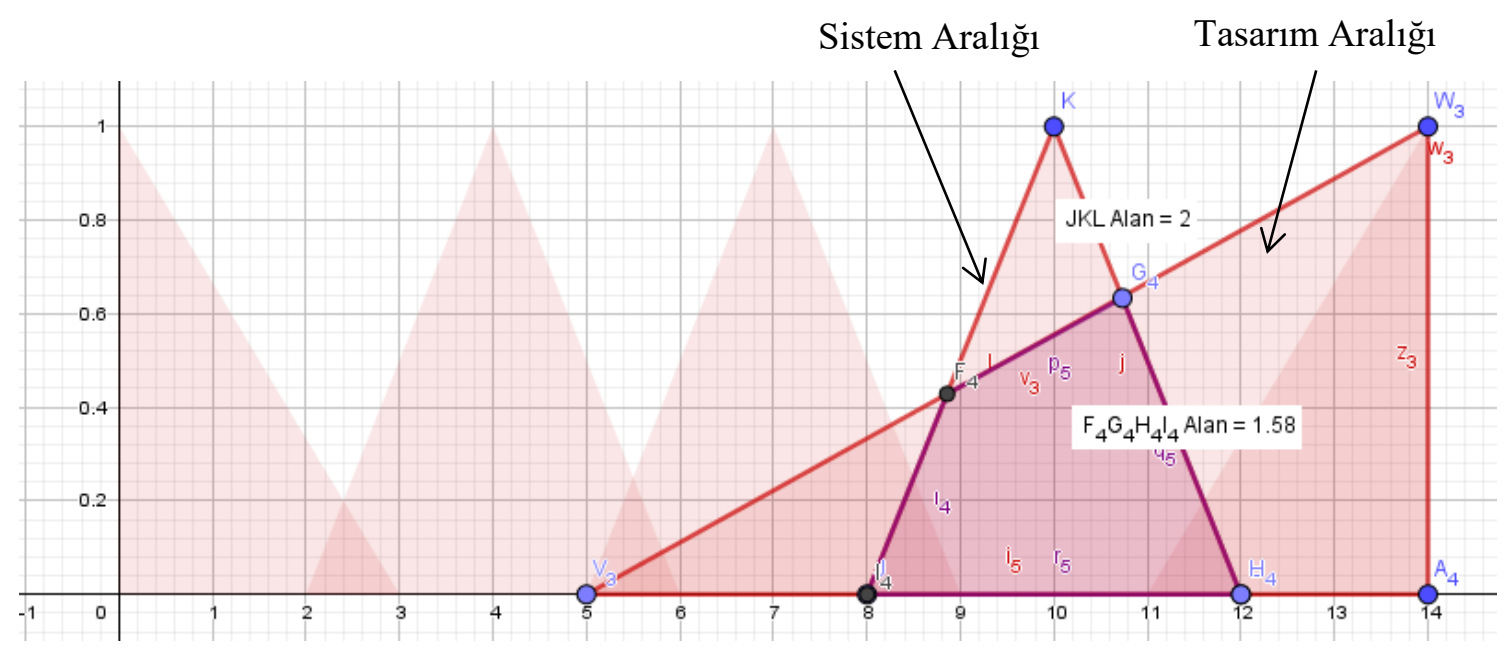

Şekil 6. 1.Üniversitenin akademik kadro açısından bilgi içeriği.

Benzer şekilde 1.üniversite için modern, bilimsel ve teknolojik altyapı açısından bilgi içeriği hesaplanmış ve Şekil 7'de modellenmiştir.

$$
\boldsymbol{I}_{\mathrm{t} 1}=\log _{2}(2 / 0,98)=0,340
$$

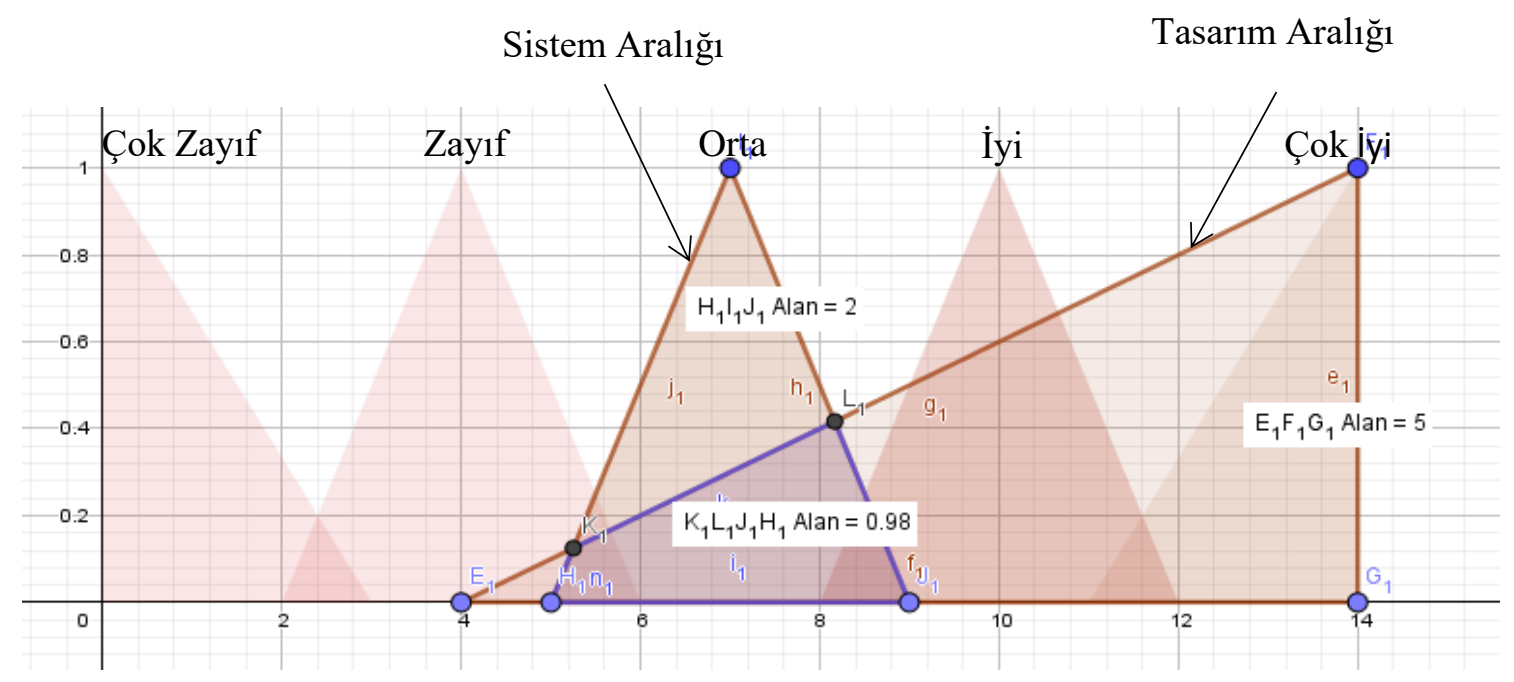

Şekil 7. 1.Üniversitenin modern, bilimsel ve teknolojik altyapı açısından bilgi içeriği.

Şekil 6 ve 7'ye göre sistem aralığ1 ve tasarım aralığı arasındaki alanlar hesaplanmış ve bilgi içeriği formülünde kullanılmıştır. Her alternatif ve her kriter için bilgi içerikleri hesaplanarak Tablo 3 oluşturulmuştur. Aksiyomatik Tasarımda en küçük bilgi içeriğini üreten alternatif, tercih edilmesi gereken alternatif olarak kabul edilir. Tablo 3 'te elde edilen sonuçlara bakıldığında en küçük bilgi içeriğine sahip alternatif 1. üniversite olduğundan bu alternatifin tercih edilmesi önerilmektedir. 
Tablo 3. Üniversiteler için bilgi içeriği sonuçları.

\begin{tabular}{lcccccc}
\hline Unniversite & $\boldsymbol{I} \boldsymbol{a} \boldsymbol{k}$ & $\boldsymbol{I} \boldsymbol{i d}$ & $\boldsymbol{i} \boldsymbol{k}$ & $\boldsymbol{I} \boldsymbol{t}$ & $\boldsymbol{I y} \boldsymbol{t}$ & $\sum \boldsymbol{I}$ \\
\hline 1. Üniversite & 0,34 & 0 & 0,34 & 1,029 & 0,176 & $\mathbf{1 , 8 8 5}$ \\
2. Üniversite & 1,454 & 3,184 & 0,34 & 1,029 & 0 & $\mathbf{6 , 0 0 8}$ \\
3. Üniversite & 0,34 & 0 & 0,34 & 1,029 & 5,644 & $\mathbf{7 , 3 5 3}$ \\
4. Üniversite & 0 & 0,633 & 0 & 3,556 & 0 & $\mathbf{4 , 1 8 9}$ \\
5. Üniversite & 0,34 & 0,633 & 0,34 & 0,26 & 0,621 & $\mathbf{2 , 1 9 4}$ \\
6. Üniversite & 2 & 0 & 0,811 & 0 & 1,644 & $\mathbf{4 , 4 5 5}$ \\
\hline
\end{tabular}

Burada, üniversite tercihine etki eden faktörlerin eşit öneme sahip olduğu varsayllarak işlemler yapılmıştır. Ancak gerçek hayatta kriterlerin önem dereceleri birbirlerinden farklı olabilmektedir. Ağıllıklı aksiyomatik tasarım, kriterlerin farklı önem derecelerine sahip olması durumunda kullanılabilmektedir. Aşağıdaki bölümde buna yer verilmiştir. Öncelikle, kriterlerin ağırlıkları normal AHP ile değilde bulanık AHP yöntemi ile hesaplanmıştır. Bulanık AHP, karar vericilerin dilsel olarak ifade ettikleri önem derecelerini ele alarak işlem yapabildiği için tercih edilmiştir. Bununla birlikte önem derecelerini bulmada bu yöntemin oldukça yaygın olarak kullanılmasının sebebi ise yöntemin etkili ve kolay sonuç vermesi olarak gösterilebilir.

\subsection{Ağırlıklı bulanık aksiyomatik tasarım uygulaması}

\subsection{1 Ăğılıkların bulanık AHP ile hesaplanması}

Karar vermede etkili olan kriterler her zaman eşit önem derecesine sahip olmayabilir. Böyle durumlarda ağırlıklı bulanık Aksiyomatik Tasarıma başvurulabilir. Bu yöntemde öncelikle her kriter için ağırlıklar hesaplanmalıdır. Burada ağırlıklar bulanık AHP yöntemi ile elde edilmiştir. Literatürde bu yöntemle ilgili oldukça zengin kaynak bulunduğundan burada detayları verilmemiştir. Hesap edilen ağırlıklar Tablo 4'de verilmiştir.

Tablo 4. Bulanık AHP kullanılarak hesap edilen ağırlıklar.

\begin{tabular}{lc}
\hline Kriterler & A ğırlıklar \\
\hline Akademik Kadro & 0,321 \\
İş Dünyası İle Etkileşim & 0,202 \\
Sosyal Kültürel Olanaklar & 0,031 \\
Modern, Bilimsel, Teknolojik Altyapı & 0,242 \\
Yurt İmkânı & 0,204 \\
\hline
\end{tabular}

Ağırlıklandırılmış bulanık Aksiyomatik Tasarımın normal Aksiyomatik Tasarımdan tek farkı hesaplanan bilgi içeriklerine ağırlıkların dahil edilmesidir. Örnek olması açısından Denklem 9'a göre birkaç ağırlıklandırılmış bilgi içeri hesabı verilmiştir.

Birinci Üniversite için akademik kadro bilgi içeriği;

$0 \leq 0,340 \leq 1 \quad I=\log _{2}(2 / 1,58)^{(1 / 0,321)}=0,0346$

İkinci Üniversite için akademik kadro bilgi içeriği; 


$$
1,454 \geq 1 \quad I=\log _{2}\left(1,454^{0,321}\right)=1,1276
$$

Ağırlıklandırılmış bilgi içeriği hesabında normal bulanık Aksiyomatik Tasarımdan gelen bilgi içeriklerinin 1'den küçük olması, 1'e eşitliği , veya 1'den büyük olma durumuna göre bilgi içeriği hesabı değişmektedir. Tablo 5'de Bulanık AHP ile ağırlıkları hesaplanarak elde edilen bilgi içeriği sonuçlarına baktığımızda bilgi içeriği toplamı en düşük değere sahip olan 5. üniversitenin tercih edilmesi önerilmektedir.

Tablo 5.A ğırlıklandırılmış bulanık aksiyomatik tasarım için bilgi içeriği sonuçları.

\begin{tabular}{llllllc}
\hline \multicolumn{1}{c}{ Üniversite } & $\boldsymbol{I a k}$ & $\boldsymbol{I i d}$ & $\boldsymbol{I} \boldsymbol{k}$ & $\boldsymbol{I t}$ & $\boldsymbol{I} \boldsymbol{t}$ & $\sum \boldsymbol{I}$ \\
\hline 1.Üniversite & 0,0346 & 0,0000 & 0,0000 & 1,0070 & 0,0002 & $\mathbf{1 , 0 4 2}$ \\
2.Üniversite & 1,1276 & 1,2632 & 0,0000 & 1,0070 & 0,0000 & $\mathbf{3 , 3 9 8}$ \\
3.Üniversite & 0,0346 & 0,0000 & 0,0000 & 1,0070 & 1,4236 & $\mathbf{2 , 4 6 5}$ \\
4.Üniversite & 0,0000 & 0,1033 & 0,0000 & 1,3599 & 0,0000 & $\mathbf{1 , 4 6 3}$ \\
5.Üniversite & 0,0346 & 0,1033 & 0,0000 & 0,0039 & 0,0969 & $\mathbf{0 , 2 3 9 *}$ \\
6.Üniversite & 1,2489 & 0,0000 & 0,0012 & 0,0000 & 1,1068 & $\mathbf{2 , 3 5 7}$ \\
\hline
\end{tabular}

Bulanık aksiyomatik tasarım ve ağırlıklı bulanık aksiyomatik tasarım ile yapılan sıralamanın karşılaştırma sonuçları Tablo 6' da verilmiştir.

Tablo 6.Yapılan aksiyomatik tasarım çalışmalarının karşılaştırılması.

\begin{tabular}{|c|c|c|}
\hline Üniversiteler & $\begin{array}{c}\text { Bulanık Aksiyomatik } \\
\text { Tasarım }\end{array}$ & $\begin{array}{c}\text { Ağırlıklı Bulanık Aksiyomatik } \\
\text { Tasarım }\end{array}$ \\
\hline 1. Üniversite & 1.S1rada & 2.Sirada \\
\hline 2.Üniversite & 5.Sirada & 6.Sirada \\
\hline 3.Üniversite & 6.S1rada & 5.Sirada \\
\hline 4.Üniversite & 3.Sirada & 3.Sirada \\
\hline 5.Üniversite & 2.Sirada & 1.S1rada \\
\hline 6.Üniversite & 4.Sirada & 4.Sirada \\
\hline
\end{tabular}

Tablo 6'da verilen sonuçlara göre bulanık aksiyomatik tasarım uygulandı̆̆ında 1. Üniversitenin tercih edilmesi önerilmektedir. Ancak ağırlıklı bulanık aksiyomatik tasarım uygulandığında ise 5. Üniversitenin tercih edilmesi önerilmektedir. Kriterlerin önem derecelerinin farklı olduğu göz önünde bulundurularak yapılan ikinci değerlendirmede farklı alternatifin önerilmesi beklenen bir durumdur. Burada hem kriterlerin önemlerinin eşit düzeyde olması, hem de farklı düzeyde olması durumlarında aksiyomatik tasarımın kullanılabileceği ve çeşitli çok kriterli karar verme problemleri için de etkili olacağı gösterilmiştir.

\section{Sonuç}

Bulanık Aksiyomatik Tasarımda sistem ve tasarım aralığı arasındaki alan hesaplanarak aslında istenilen kriterleri en iyi düzeyde karşılayan alternatifleri tespit edebilme amaçlanır. Böylelikle Aksiyomatik Tasarımın istenilen kriterleri daha yüksek oranda 
karşılayan alternatifi bulabilmesi, onu bu yönüyle diğer çok kriterli karar verme tekniklerinden ayırır.

Üniversite seçimi öğrencilerin gelecek hayatlarını etkileyen en önemli parametrelerden biridir. Her üniversitenin kendine ait bir altyapısı ve olanakları mevcuttur. Üniversite seçimini etkileyen kriterler sayısal olarak ifade edilemediği durumlarda dilsel olarak ifade edilir.

Bu çalışmada öncelikle uzman kişiler tarafından üniversite seçimini etkileyen kriterlerin tasarım aralıkları belirlenmiş ve ardından her üniversite için o üniversitede okuyan öğrencilere danışılarak sistem aralıkları belirlenmiştir. Sistem ve tasarım aralıkları belirlendikten sonra ortak alanlar hesaplanarak bilgi içerikleri hesaplanmıştır.

Gerçek hayatta her bir kriterin ağırlığı aynı olmayacağından ikinci bir uygulama olarak Ağırlıklı Bulanık Aksiyomatik Tasarım uygulaması gerekmektedir. Bunun için 6 öğrenciden kriterlerin birbirlerine göre önem derecelerini kıyaslamaları istenmiş ve her kriter için Bulanık AHP metoduyla ağırlıklar hesaplanmıştır. Sonuçlar incelendiğinde Ağırlıklandırılmış Bulanık Aksiyomatik Tasarım ile Bulanık Aksiyomatik Tasarım uygulamalarında hesaplanan toplam bilgi içeriklerinin farklı olduğu, seçilen üniversite tercihinin değisștiği gözlemlenmiştir. Gerçek hayatta kriterlerin önem dereceleri görece birbirlerinden farklı olabileceği için her iki uygulamada da aynı alternatifin önerilmemesi olası bir durumdur. Burada hem kriterlerin önemlerinin eşit düzeyde olması, hem de farklı düzeyde olması durumlarında aksiyomatik tasarımın kullanılabileceği gösterilmiştir. Çeşitli kriterlere sahip farklı karar problemlerinde de bulanık aksiyomatik tasarım yöntemi kullanılabilecektir.

\section{Kaynakça}

[1] Sarıkaya, T. ve Khorshid, T., Üniversite öğrencilerinin meslek seçimini etkileyen etmenlerin incelenmesi: Üniversite öğrencilerininmeslek seçimi, Türk Eğitim Bilimleri Dergisi, 7(2), 393-423, (2009).

[2] Yaman, T. T., \& Çakır, Ö., Üniversite tercihlerini etkileyen faktörlerin seçime dayalı konjoint analizi ile belirlenmesi, MAKÜ-Uygulamalı Biimler Dergisi, 6584, (2017).

[3] Veloutsou, C., and, J. W., \& Paton, R. A., University selection:information requirements and importance, International Journal of Educational Management, (2006).

[4] Fuller, M. A., \& Delorey, R., Making the choice: University and program selection factors for undergraduate management education in Maritime Canada, The International Journal of Management Education, 176-186, (2016).

[5] Polat, S., The factors that students consider in university and department selection: A qualitative and quantitative study of Kocaeli University, Faculty of Education students, Procedia - Social and Behavioral Sciences, 2140 - 2145, (2012).

[6] Özel, B., \& Özyörük, B., Bulanık aksiyomatik tasarım ile tedarikçi firma seçimi, Gazi Üniversitesi Mühendislik Mimarlık Fakültesi Dergisi, 22(3), 415-423, (2007)

[7] Batur, D.G., Özyürek, B., Aksiyomatik tasarım ile tedarikçi seçimi: bebek mamasi üretimi için türkiye'de bir uygulama, Bilişim Teknolojileri Dergisi, 11(2), 195201, (2018). 
[8] Chang, D.-Y., Applications of the Extent Analysis Method on Fuzzy AHP, European Journal of Operational Research, 95(3), 649-655, (1996).

[9] Güner, H., Bulanık AHP ve Bir İşletme için Tedarikçi Seçimi Problemine Uygulanmas1, Pamukkale Üniversitesi Fen Bilimleri Enstitüsü, Yayımlanmamış Yüksek Lisans Tezi, (2005).

[10] Mahmoodzadeh, S. J., Project Selectionby Using Fuzzy AHP and TOPSIS Technique, World Academy of Science, Engineering and Technology, Vol:30; 333-338, (2007)

[11] Kahraman, C., Cebeci, U., \& Ulukan, Z., Multi-criteria Supplier Selection Using Fuzzy AHP, Logistics Information Management, 16(6); 382-394, (2003).

[12] Suh, N. P., Axiomatic Design Theory for Systems, Research in Engineering, 189-209, (1998).

[13] Suh, N.P., Axiomatic Design-Advances and Applications, Oxford University Press, New York, (2001).

[14] Murat Y.Ş. ve Kulak O., Ulaşım Ağlarında Bilgi Aksiyomu Kullanılarak Güzergah (Rota) Seçimi, Mühendislik Bilimleri Dergisi, 11(3), (2005).

[15] Osman Kulak, C. K., Fuzzy multi-attribute selection among transportation, Information Sciences, 191-210, (2005). 